\title{
Increasing butyrate concentration in the distal colon by accelerating intestinal transit
}

\author{
S J Lewis, K W Heaton
}

\begin{abstract}
Background-Populations at low risk of colonic cancer consume large amounts of fibre and starch and pass acid, bulky stools. One short chain fatty acid (SCFA), butyrate, is the colon's main energy source and inhibits malignant transformation in vitro.

Aim-To test the hypothesis that altering colonic transit rate alters colonic $\mathrm{pH}$ and the SCFA content of the stools.

Patients-Thirteen healthy adults recruited by advertisement.

Methods-Volunteers consumed, in turn, wheat bran, senna and loperamide, each for nine days with a two week washout period between study periods, dietary intake being unchanged. Before, and in the last four days of each intervention, whole gut transit time (WGTT), defaecation frequency, stool form, stool $\beta$-glucuronidase activity, stool $\mathrm{pH}$, stool SCFA concentrations and intracolonic $\mathbf{p H}$ (using a radiotelemetry capsule for continuous monitoring) were assessed.

Results-WGTT decreased, stool output and frequency increased with wheat bran and senna, vice versa with loperamide. The pH was similar in the distal colon and stool. Distal colonic $\mathrm{pH}$ fell with wheat bran and senna and tended to increase with loperamide. Faecal SCFA concentrations, including butyrate, increased with senna and fell with loperamide. With wheat bran the changes were nonsignificant, possibly because of the short duration of the study. Baseline WGTT correlated with faecal SCFA concentration $(r=-0.511, p=0.001)$, with faecal butyrate $(r=-0.577, \mathrm{p}<0.001)$ and with distal colonic pH $(r=0.359, \mathrm{p}=0.029)$.

Conclusion-Bowel transit rate is a determinant of stool SCFA concentration including butyrate and distal colonic pH. This may explain the inter-relations between colonic cancer, dietary fibre intake, stool output, and stool $\mathrm{pH}$.

(Gut 1997; 41: 245-251)
\end{abstract}

Keywords: bowel cancer; colonic $\mathrm{pH}$; fibre; intestinal transit; $\mathrm{pH}$; short chain fatty acids

There are theoretical grounds for believing that high colonic $\mathrm{pH}$ is relevant in the pathogenesis of colonic cancer. ${ }^{1-3}$ When faecal $\mathrm{pH}$ has been measured in populations with a low risk of colonic cancer, it has been lower than in higher risk groups. ${ }^{245}$ Faecal and colonic $\mathrm{pH}$ are chiefly determined by a balance between the production and absorption of the weak base, ammonia, and of the weak acids, the short chain fatty acids (SCFA). Ammonia and SCFA are produced in the colon by bacterial fermentation of protein and carbohydrate, respectively, most of which are derived from the diet. ${ }^{6}$ Short chain fatty acids are produced by fermentation of carbohydrates that have escaped absorption in the small intestine, notably starch and non-starch polysaccharide (NSP, dietary fibre). As the colon is traversed SCFA are absorbed and the luminal $\mathrm{pH}$ gradually increases to around neutral. ${ }^{7}$ This rise in $\mathrm{pH}$ fails to occur in rural Africans (who have a low risk of colonic cancer). ${ }^{8}$ The preservation of colonic acidity in Africans could be a result of the high polysaccharide content of their diet providing surplus substrate for SCFA production. Alternatively, it could be caused by the more rapid colonic transit reported to be characteristic of rural Africans, ${ }^{9} 10$ delaying the absorption of SCFA, or to a combination of the two. If transit rate is important, it should be possible to mimic the African situation by accelerating transit by using laxatives.

One SCFA, butyrate, is the colon's main source of energy and has several properties suggesting it has anti-neoplastic activity. ${ }^{11}$ Recently, it has been shown to be protective against malignant transformation in vitro. ${ }^{12}$ High colonic $\mathrm{pH}$ is likely to be associated with low levels of butyrate in the distal colon and thus increased predisposition to cancer. Although studies have provided conflicting data, increasing faecal SCFA concentration (and thus distal colonic concentration) has been shown to reduce distal colonic cell proliferation, ${ }^{13}$ and in dimethylhydralazine treated rats it reduces malignant transformation. ${ }^{14}$

We set out to test the hypothesis that colonic transit rate influences colonic $\mathrm{pH}$ and the SCFA, including butyrate, content of the stools, dietary intake being unchanged. We used wheat bran as well as senna to speed up transit. Bran was expected to have a substantial effect, as previous reports indicate that it lowers stool $\mathrm{pH}^{15}$ and increases faecal SCFA levels. ${ }^{16}{ }^{17}$ Potential tumour promoters such as deoxycholic acid and steroids (that is, oestrogens) are dependent for their production on $\mathrm{pH}$ sensitive bacterial enzymes in the colon. ${ }^{18-20}$ These enzymes include $\beta$-glucuronidase. We therefore measured faecal $\beta$-glucuronidase activity to determine whether this also changed with alteration of colonic transit rate. 


\section{Subjects and Methods}

Thirteen adults were recruited through advertisements placed in local hospitals. Volunteers were selected if they were omnivorous, healthy, on no medication, and not obese or pregnant. All were by chance non-smokers. The study was approved by the Research Ethics Committee of the United Bristol Healthcare Trust.

Raw wheat bran (Prewett's, sieved to contain only particles $1.4-3.0 \mathrm{~mm}$ diameter) and senna tablets (Senokot, Reckitt and Coleman), were used to accelerate intestinal transit. Loperamide tablets (Imodium, Janssen Pharmaceuticals) were used to slow down transit. Each agent was taken for nine days and there were two to four week washout periods between agents to obviate any carryover effects. Each agent was taken in the maximum tolerated dose. Wheat bran was taken in divided doses with meals. The interventions were studied in a set order (wheat bran, senna, loperamide) because successful randomisation would have required an impracticably large number of volunteers to ensure a balanced distribution between the six possible orders.

Before and at the end of each intervention period volunteers were weighed and their height measured to calculate their body mass index and asked to complete a four day dietary record (two week days and two weekend days) using scales or household measures. Where insufficient dietary information was recorded the subjects were telephoned for clarification. The records were analysed for individual nutrients (total energy, total fibre (Southgate), insoluble non-starch polysaccharide (NSP), soluble NSP, total NSP, total fat, saturated fat, polyunsaturated fat, protein, carbohydrate, extrinsic sugar, and alcohol) using a computer program based on McCance and Widdowson's food tables ${ }^{21}$ and the publications of Englyst et $a l^{2223}$

Before and at the end of each intervention period whole gut transit time (WGTT) was measured as a proxy for colonic transit by a modification of a published method. ${ }^{24}$ Twenty radio-opaque marker pellets contained within a capsule were swallowed (different shapes each day) on each of four consecutive mornings. The first two stools passed at least 24 hours after ingestion of the last set of markers were collected, flattened and radiographed. By counting the number of markers in each stool then applying the following formula the mean WGTT was calculated from the two stools.

WGTT $(\mathrm{h})=\left(t_{1} s_{1}+t_{2} s_{2} \ldots+t_{8} s_{8}\right) /\left(s_{1}+s_{2} \ldots+s_{8}\right)$

where $s=$ number of markers of a given shape in a stool sample, that is, $0-20$, and $t=$ time in hours since ingestion of this marker pellet to the passing of the stool. The subscripts 1-8 identify the four different shapes of marker pellet in the two stool samples. Thus, there are up to four types of pellets in each stool, identified by subscripts $1-4$ in the first and $5-8$ in the second stool.

Within 12 hours of passing, the stools were weighed and the second stool was liquidised, tested for $\mathrm{pH}$ with a Gelplas combination $\mathrm{pH}$ electrode probe, then frozen at $-20^{\circ} \mathrm{C}$ for later $\beta$-glucuronidase activity analysis by using a modification of an established method. ${ }^{25} \mathrm{~A}$ pilot study had shown that stool $\mathrm{pH}$ did not vary significantly within 24 hours of defaecation.

Stool output per week was calculated as the mean weight of the two collected stools multiplied by the subject's stated number of defaecations per week. Volunteers also completed a diary of their stool appearance, on a 1-7 scale, which is sensitive to transit time ${ }^{2627}$ and of dates and times, enabling the calculation of interdefaecatory intervals (IDI).

The $\mathrm{pH}$ sensitive, radio-transmitting capsule (see below) was swallowed with the third day marker capsule. The capsule and markers were taken in the morning after an overnight fast, volunteers being asked not to eat or drink for the next hour.

The experimental agents were commenced immediately after completion of baseline assessments and continued until the ontreatment assessments of dietary intake and WGTT were completed.

\section{pH RADIOTELEMETRY}

The $\mathrm{pH}$ sensitive capsule comprises a transducer, battery, and radio transmitter sealed in a glass capsule ${ }^{7}$ (Remote Control Systems, Amersham, UK). The capsule was calibrated before each use in buffers at $\mathrm{pH} 9.1$ and 4.0 at $37^{\circ} \mathrm{C}$ and the $90 \%$ response time (an indication of the battery's reliability) was measured. This gives the time for the capsule to attain $90 \%$ of the total change in $\mathrm{pH}$ after transfer from one of the buffers to the other. After each use the capsule was cleaned and a further calibration check was done. If the $\mathrm{pH}$ of either buffer was now over- or under-recorded by $\geqslant 0.2 \mathrm{pH}$ units or the response time was greater than three seconds, the study was rejected and repeated.

The $\mathrm{pH}$ readings were downloaded to a computer for analysis using Flexisoft II ambulatory $\mathrm{pH}$ analysis software (Oakfield Instruments, Witney, UK). For each part of the colon a mean value was calculated. For analysis the following conventions were followed ${ }^{7}$ : proximal colon, first four hours of colonic recording; distal colon, last four hours of recording; mid colon, four hours midway between the proximal and distal recording periods.

Short chain fatty acids were measured by gas-liquid chromatography on a packed column (Chromosorb WAW10\% SP 1200/1\% $\mathrm{H}_{3} \mathrm{PO}_{4}$ ) of diethyl ether extracts. ${ }^{28}$ We used $\beta$-methyl valeric acid as an internal standard and a mixed SCFA external standard. The temperature program was $110-150^{\circ} \mathrm{C}$ at $16^{\circ} \mathrm{C} /$ min with two minutes at $110^{\circ} \mathrm{C}$ and two minutes at $150^{\circ} \mathrm{C}$. Calibration curves were obtained by chromatographing standard solutions at five different concentration levels. The calibration curves were prepared by plotting the area ratios (weight of active per weight of internal standard). 
TABLE 1 Demographic data and anthropomorphic measurements at entry into the study

\begin{tabular}{lll}
\hline & Men $(n=3)$ & Women $(n=10)$ \\
\hline Age & $42(31-43)$ & $34(23-58)$ \\
Height $(\mathrm{cm})$ & $181(178-183)$ & $163(149-174)$ \\
Weight $(\mathrm{kg})$ & $78(67-84)$ & $65(48-2)$ \\
Waist $(\mathrm{cm})$ & $84(79-90)$ & $76(65-4)$ \\
Hip (cm) & $100(99-110)$ & $101(72-12)$ \\
Waist/hip & $0.8(0.76-0.90)$ & $0.77(0.68-0.90)$ \\
BMI & $23.8(20.0-26.5)$ & $23.8(18.6-32.2)$ \\
$\begin{array}{l}\text { Alcohol } \quad \text { (units/week) } \\
\quad 2.0(0.0-8.0)\end{array}$ & $3.5(0.0-10.0)$ \\
\hline
\end{tabular}

Results expressed as median (range).

Data were assessed as parametrically or nonparametrically distributed by Ryan Joiner tests and bar histograms and were expressed as means with standard deviations or medians with interquartile ranges. Changes from baseline were assessed for significance by using paired two-tailed Student's $t$ and Wilcoxon rank sum tests as appropriate. Associations were assessed by using Spearman correlation coefficients. These were calculated on the pooled off-treatment readings to determine whether the artificial changes produced by the experiments had any counterpart in spontaneous variations.

\section{Results}

Of the 13 volunteers (three male, 10 female) who entered the study (table 1), 11 completed all the protocols. Two women with long basal WGTT measurements withdrew from the loperamide section of the study. Consumption of wheat bran averaged (SD) 28.3 (8.7) g/day. Table 2 shows that the intended changes occurred in WGTT, namely reductions with bran and senna (greater with senna) and an increase with loperamide. These were reflected in higher stool output with bran and senna (again greater with senna) and lower stool output with loperamide, though the first two changes just escaped statistical significance. The expected changes also occurred in the frequency of defaecation and in stool form, and all these were significant (table 2).

In the proximal colon (mean baseline $\mathrm{pH}$ 5.21) there were no significant changes in $\mathrm{pH}$ with any of the three interventions (data not shown). In the mid colon senna induced a significant fall averaging $0.46 \mathrm{pH}$ units but with bran there was only a non-significant trend in the same direction (table 3). In the distal colon senna again induced a substantial drop in $\mathrm{pH}$, averaging $0.48 \mathrm{pH}$ units, and here wheat bran too had a significant acidifying effect. Loperamide was without effect in both the mid and distal colon. Stool $\mathrm{pH}$ did not significantly change with any intervention though there were trends in the expected direction with senna and loperamide.

Faecal SCFA concentrations were affected in a consistent manner but in opposing directions by senna and loperamide (table 4). Acetic, propionic, and butyric acid concentrations all rose substantially with senna. The biggest increase was with butyric acid which rose more than threefold. Loperamide caused substantial reductions in propionic and butyric acids; the fall with acetic acid just escaped statistical significance. Bran resulted only in nonsignificant trends, albeit in the expected direc-

TABLE 2 Changes in transit time and defaecatory measurements (median, interquartile range) with wheat bran, senna and loperamide

\begin{tabular}{|c|c|c|c|c|c|c|c|}
\hline & Baseline & & Active & & Difference & $95 \% C I$ & $p$ Value \\
\hline \multicolumn{8}{|c|}{ Whole gut transit time (hours) } \\
\hline Wheat bran & 69.0 & $(45.8$ to 83.1$)$ & 39.0 & (32.0 to 75.8 ) & -13.6 & -50.8 to -2.5 & 0.038 \\
\hline Senna & 69.0 & (50.1 to 83.9$)$ & 41.0 & (31.4 to 49.9$)$ & -33.9 & -41.5 to -12.5 & 0.004 \\
\hline Loperamide & 50.3 & (35.7 to 65.0 ) & 74.0 & (61.3 to 97.0$)$ & 22.3 & 15.6 to 69.8 & 0.004 \\
\hline \multicolumn{8}{|c|}{ Calculated stool output (g/week) } \\
\hline Wheat bran & 602 & (401 to 900$)$ & 840 & (466 to 1609 ) & 280 & -13 to 766 & 0.059 \\
\hline Senna & 658 & ( 550 to 1344 ) & 1487 & (794 to 2499 ) & 633 & -42 to 1159 & 0.059 \\
\hline Loperamide & 1049 & (588 to 1659 ) & 315 & (189 to 665$)$ & -469 & -1331 to -156 & 0.009 \\
\hline \multicolumn{8}{|c|}{ Interdefaecatory intervals (hours) } \\
\hline Wheat bran & 24.0 & (19.2 to 24.0$)$ & 18.0 & (13.5 to 24.0$)$ & -6.0 & -10.2 to -0.5 & 0.023 \\
\hline Senna & 24.0 & (22.5 to 24.0$)$ & 16.0 & (11.5 to 19.6$)$ & -8.0 & -16.0 to -4.0 & 0.005 \\
\hline Loperamide & 24.0 & (17.0 to 24.0 ) & 36.0 & (24.0 to 48.0$)$ & 16.0 & 3.9 to 24.0 & 0.019 \\
\hline \multicolumn{8}{|c|}{ Stool form scores ${ }^{*}($ mean $(S D))$} \\
\hline Wheat bran & 3.5 & $(0.7)$ & 4.3 & $(1.2)$ & 0.8 & 0.1 to 1.6 & 0.025 \\
\hline Senna & 3.6 & $(0.9)$ & 4.6 & $(0.6)$ & 0.9 & 0.3 to 1.5 & 0.005 \\
\hline Loperamide & 4.2 & $(0.7)$ & 2.8 & $(1.2)$ & -1.5 & -2.2 to -0.7 & 0.001 \\
\hline
\end{tabular}

*The stool form scale ranges from 1 (hard round lumps) to 7 (watery), so a rise in the score represents an acceleration of colonic transit. ${ }^{2627}$

TABLE 3 pH in the mid and distal colon and in the stool before and during treatment with wheat bran, senna and loperamide

\begin{tabular}{|c|c|c|c|c|c|c|c|}
\hline & Before & & During & & Difference & $95 \% C I$ & $p$ Value \\
\hline \multicolumn{8}{|l|}{ Mid colon } \\
\hline Wheat bran & 6.83 & $(0.39)$ & 6.59 & $(0.48)$ & -0.24 & -0.57 to 0.09 & 0.140 \\
\hline Senna & 6.85 & $(0.48)$ & 6.39 & $(0.48)$ & -0.46 & -0.87 to -0.04 & 0.035 \\
\hline Loperamide & 6.89 & $(0.46)$ & 6.96 & $(0.39)$ & 0.07 & -0.31 to 0.44 & 0.700 \\
\hline \multicolumn{8}{|l|}{ Distal colon } \\
\hline Wheat bran & 7.08 & $(0.47)$ & 6.88 & $(0.43)$ & -0.20 & -0.38 to -0.02 & 0.033 \\
\hline Senna & 7.14 & $(0.52)$ & 6.66 & $(0.48)$ & -0.48 & -0.93 to -0.03 & 0.039 \\
\hline Loperamide & 7.11 & $(0.25)$ & 7.15 & $(0.37)$ & 0.04 & -0.29 to 0.37 & 0.800 \\
\hline \multicolumn{8}{|l|}{ Stool } \\
\hline Wheat bran & 6.82 & $(0.73)$ & 6.80 & $(0.52)$ & -0.03 & -0.52 to 0.47 & 0.910 \\
\hline Senna & 6.99 & $(0.67)$ & 6.70 & $(0.35)$ & -0.29 & -0.76 to 0.18 & 0.210 \\
\hline Loperamide & 6.89 & $(0.42)$ & 7.22 & $(0.53)$ & 0.32 & -0.20 to 0.84 & 0.200 \\
\hline
\end{tabular}

Results expressed as mean (SD). 
TABLE 4 Faecal SCFA concentrations before and during treatment ( $\mu \mathrm{mol} / \mathrm{g}$ wet weight)

\begin{tabular}{|c|c|c|c|c|c|c|c|}
\hline & Baseline & & Active & & Difference & $95 \% C I$ & $p$ Value \\
\hline \multicolumn{8}{|l|}{ Acetic acid* } \\
\hline Wheat bran & 72.9 & $(41.5)$ & 81.0 & $(25.7)$ & 8.1 & -14.8 to 31.1 & 0.460 \\
\hline Senna & 63.9 & (32.5) & 138.2 & $(56.4)$ & 74.3 & 37.1 to 111.5 & $>0.001$ \\
\hline Loperamide & 79.8 & $(39.2)$ & 51.6 & $(31.6)$ & -28.2 & -57.5 to 1.1 & 0.057 \\
\hline \multicolumn{8}{|l|}{ Propionic acidt } \\
\hline Wheat bran & 24.0 & (14.2 to 34.7$)$ & 21.9 & (14.6 to 28.7 ) & 3.4 & -14.4 to 4.9 & 0.890 \\
\hline Senna & 18.4 & (13.6 to 29.9 ) & 40.3 & (22.5 to 59.8 ) & 18.6 & 4.6 to 33.1 & 0.025 \\
\hline Loperamide & 27.2 & (18.9 to 37.3$)$ & 16.6 & (9.3 to 30.4 ) & -4.3 & -16.1 to -1.1 & 0.018 \\
\hline \multicolumn{8}{|l|}{ Butyric acidt } \\
\hline Wheat bran & 69.0 & (21.8 to 128.6$)$ & 79.4 & (32.8 to 102.3 ) & 0.0 & -35.4 to 27.6 & 1.000 \\
\hline Senna & 16.6 & (5.0 to 24.2 ) & 59.1 & (29.2 to 82.4$)$ & 38.9 & 15.5 to 65.0 & 0.006 \\
\hline Loperamide & 24.8 & (17.9 to 45.9$)$ & 6.0 & $(0.0$ to 37.0$)$ & -11.8 & -23.3 to -0.8 & 0.032 \\
\hline \multicolumn{8}{|l|}{ Total SCFAt } \\
\hline Wheat bran & 95.0 & (64.5 to 167.5 ) & 113.0 & (90.5 to 149.5 ) & 11.8 & -24.0 to 34.5 & 0.750 \\
\hline Senna & 111.0 & (72.5 to 161.0 ) & 202.0 & (162.0 to 226.5 ) & 76.0 & 26.5 to 120.5 & 0.005 \\
\hline Loperamide & 152.0 & (86.0 to 197.0 ) & 82.0 & (65.0 to 130.0 ) & -28.0 & -101.0 to -1.5 & 0.045 \\
\hline
\end{tabular}

${ }^{\star}$ Results expressed as mean (SD); †expressed as median (interquartile range).

tion. Because changes in WGTT with wheat bran were not as impressive as those induced by senna, we looked at the subjects consuming wheat bran who showed the greatest reduction in WGTT $(n=6)$. Changes in stool acetic acid (158-249 $\mu \mathrm{mol} / \mathrm{g}$ wet weight, $\mathrm{p}=0.015,95 \%$ confidence interval (CI) 8.17-47.15), propionic $(55-58 \mu \mathrm{mol} / \mathrm{g}$ wet weight, $\mathrm{p}=0.059,95 \%$ CI $0.26-8.73)$ and butyric acid $(43-81 \mu \mathrm{mol} / \mathrm{g}$ wet weight, $\mathrm{p}=0.59,95 \%$ CI 2.3-13.9) were seen. Senna increased valeric acid concentrations, but there were no changes in the branched chain acids isobutyric and isovaleric acid (which were present at very low concentrations) with any of the interventions (data not shown).

Faecal $\beta$-glucuronidase activity (geometric mean, $\mathrm{mmol} / \mathrm{g} / \mathrm{h}$ ) fell with wheat bran from 42 (95\% CI, 29-61) to 28 (21-39) with the difference of the $\log _{10}$ transformed data being -1.49 (ratio of the geometric means -2.06 to -1.08 ; $\mathrm{p}=0.019)$. The fall in activity with senna and rise in activity with loperamide were not significant.

No changes were seen in dietary intakes between the baseline records and the records done during the interventions (excluding wheat bran supplements). The average (SD) baseline NSP intake was 13.0 (3.8) g/day equivalent to $19.3(5.2) \mathrm{g} /$ day of dietary fibre (Southgate).

In the pooled off-treatment data $(n=37)$ there were significant associations between WGTT and faecal SCFA concentrations (fig 1, $r=-0.511, \mathrm{p}=0.001$ ), between WGTT and faecal butyric acid concentrations (fig 2, $r=-0.577, \mathrm{p}<0.001)$ and between WGTT and distal colonic $\mathrm{pH}$ (fig 3, $r=0.359, \mathrm{p}=0.029$ ). Distal colonic $\mathrm{pH}$ was significantly associated with stool butyrate concentration $(r=-0.343$, $\mathrm{p}=0.019)$ but not total SCFA concentration $(r=-0.269, \mathrm{p}=0.112)$. There was no significant association between stool $\mathrm{pH}$ and stool total SCFA or butyrate concentration.

\section{Discussion}

This study has shown that the physiochemical milieu within the colon can be profoundly altered simply by altering the rate of passage of intestinal contents. In our normal volunteers, accelerating transit with senna made the contents of the mid and distal colon more acid

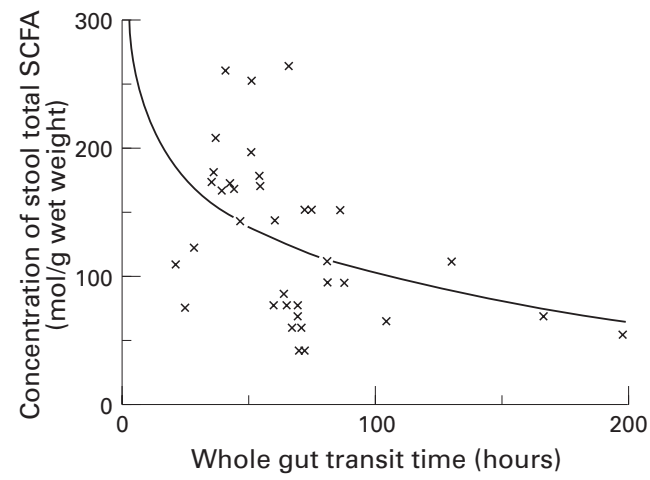

Figure 1: The relation between whole gut transit time off-treatment and total stool SCFA concentration.

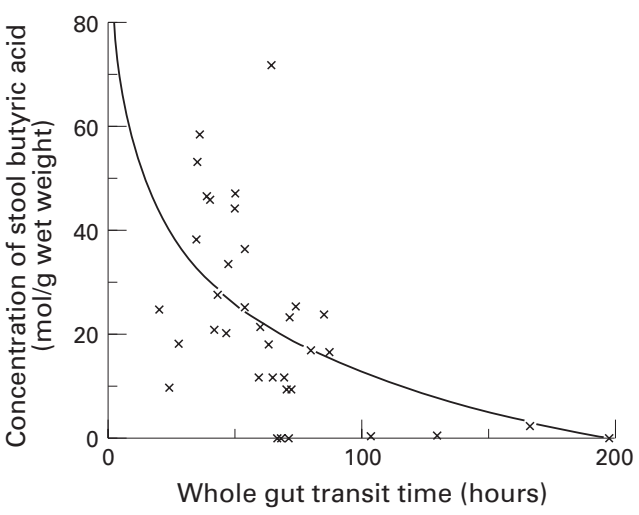

Figure 2: The relation between whole gut transit time off-treatment and stool butyrate concentration.

and increased SCFA concentrations in the stool, the greatest effect being on butyrate concentrations which tripled. Slowing down transit with loperamide reduced SCFA concentrations but had little if any effect on $\mathrm{pH}$. Do these experimental phenomena have any relevance to real life? That they may do is suggested by the correlations we found in our subjects off treatment. Whole gut transit time, a proxy for colonic transit time, was significantly correlated with faecal SCFA concentrations and, specifically, with butyrate concentration. These correlations have been recently confirmed by El Oufir et al. ${ }^{29}$ It was also, albeit weakly, correlated with $\mathrm{pH}$ in the distal colon. Since the baseline measurements of WGTT, stool weight and stool form were similar in our volunteers to those in the general population, ${ }^{26} 3031$ while 


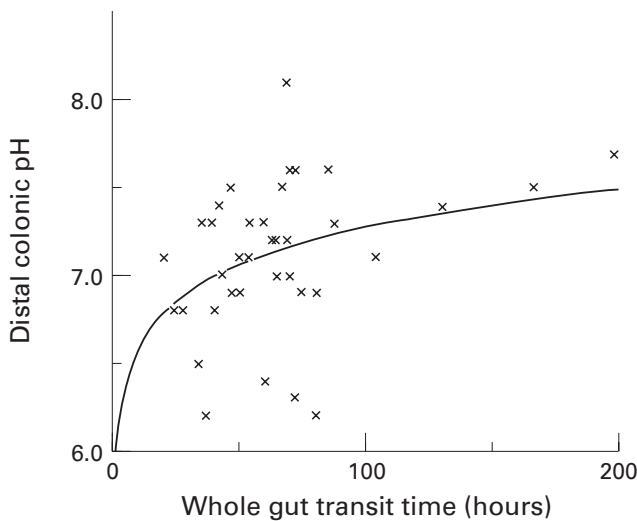

Figure 3: The relation between whole gut transit time off-treatment and distal colonic $p H$.

their colonic $\mathrm{pH}$ was similar to those in other normal volunteers, ${ }^{7}$ it is perhaps reasonable to extrapolate from our findings to the population at large.

Undoubtedly many factors contribute to the aetiology of bowel cancer but there are compelling arguments to incriminate high intraluminal $\mathrm{pH}$ and low butyrate concentrations. This being so, the present data imply that intestinal transit rate could have a significant role. The factors determining intestinal transit rate are not well understood. Transit time varies notably within and between individuals, even on a constant diet, ${ }^{32}{ }^{33}$ some of this variation being explained by psychological factors. ${ }^{34}$ Transit time is slower in women than men. ${ }^{26}{ }^{30}{ }^{35}$ An epidemiological study in Bristol identified oral contraceptive use as a transit slowing factor and alcohol use and dietary fibre intake as transit speeding factors. ${ }^{36}$ All this suggests that there may be scope for reducing the risk of bowel cancer by altering the transit time of individuals and populations.

The obvious and "natural" way to speed up transit through the intestine is to increase the intake of dietary fibre, especially wheat fibre which is particularly effective. ${ }^{37}$ It was for this reason that we studied the effect of wheat bran. We expected to find substantial falls in colonic $\mathrm{pH}$ and rises in faecal SCFA concentrations because bran and other sources of dietary fibre not only speed up transit but also provide substrate for bacterial production of SCFA. In the event, we found a modest drop in the $\mathrm{pH}$ of the distal colon but no rise in faecal SCFA concentrations (albeit trends in that direction). Changes in WGTT, stool output, interdefaecatory intervals, and stool form were less impressive than for senna or loperamide. One reason may be that our volunteers failed to take enough bran. The average dose of $28 \mathrm{~g}$ daily was as much as in most studies and as much as most people can tolerate. However, it is possible that some of our volunteers took less bran than they reported (despite our weighing their unused bran to calculate their daily consumption) or that, by chance, they were unusually insensitive to the effect of bran. On the basis that $1 \mathrm{~g}$ of fibre from raw wheat bran adds $7.2 \mathrm{~g}$ to the weight of the faeces, ${ }^{37}$ our volunteers, who ingested $28 \mathrm{~g}$ of bran daily, providing $11.2 \mathrm{~g}$ of fibre, should have increased their stool output by $81 \mathrm{~g} /$ day. In fact, median faecal weight rose to only $34 \mathrm{~g} /$ day. It is possible that the seven day study period was too short for the effect of bran to become fully apparent. In another bran feeding study faecal SCFA concentrations had increased after six weeks but not after two weeks, possibly because of the need for colonic bacteria to adapt to their new substrate.$^{16}$ Others have found that in certain people bran fails to produce the expected rise in stool weight ${ }^{38}$ or fall in transit time. ${ }^{39}$ Our findings with bran, therefore, may not accurately reflect the usual ability of wheat fibre to modify colonic function. However, we are not the first to report that faecal $\mathrm{pH}$ is unaffected by bran. ${ }^{40}$ Stephen et $a l^{40}$ found faecal $\mathrm{pH}$ to be inversely related to transit time (which we failed to do here, but have reported in other studies ${ }^{41}$ ). In humans, cellulose has been shown to lower stool $\mathrm{pH}$ while pectin failed to do so, probably because pectin is rapidly fermented and the SCFA are all absorbed, whereas cellulose is poorly fermented (fermentability is not a factor in explaining fibre's laxative effects ${ }^{37}{ }^{42}$ ) and, unlike pectin, accelerates colonic transit ${ }^{43}$ enabling the SCFA produced to reach the distal colon. Interestingly, the subgroup of volunteers taking wheat bran, and who had the largest reduction in WGTT, had a more pronounced rise in faecal SCFA concentrations.

The failure of stool total SCFA concentration to correlate significantly with stool $\mathrm{pH}$ or distal colonic $\mathrm{pH}$ (though it did with stool butyrate) was surprising, as was the failure of loperamide to raise distal colonic and stool $\mathrm{pH}$ although it lowered faecal SCFA. Presumably, other acids and bases present in the stool are important determinants of $\mathrm{pH}$. These are known to include lactate, sulphate, tartrate, succinate, and bile acids among the acids, while ammonia is the chief base. ${ }^{6}$ There is a complex interplay between dietary sources of these substances, the rate at which acids and ammonia are produced by bacterial metabolism, interactions between them, and their absorption from the colon, but it is likely that many of these processes are affected by transit through the intestine. Although our study suggests alteration of colonic transit time influences the balance between production and absorption of SCFA we are unable to comment specifically on whether the rate and extent of fermentation is altered specifically, as this may have implications on energy salvage of foods from the colon. One very unlikely caveat is that loperamide and/or senna may alter the transport rates of SCFA or the faecal bacterial flora so influencing faecal SCFA. Further studies would be needed to exclude these remote possibilities.

Bacterial enzymes are involved in the metabolism of a wide range of compounds, with the subsequent production of carcinogens. ${ }^{44}$ One such enzyme is the $\mathrm{pH}$ dependent $\beta$-glucuronidase, which as well as being responsible for deconjugating glucuronides (for example, oestrogens) also deconjugates benzo- $(a)$-pyrene glucuronides and other potential carcinogens to more toxic products. Previous work has also shown a decrease in 
$\beta$-glucuronidase activity with an increase in dietary fibre ${ }^{45-47}$ and lower levels in vegetarians compared with omnivores. ${ }^{45}$ Presumably other $\mathrm{pH}$ sensitive enzymes were similarly affected. One such enzyme is the bile acid $7 \alpha-$ dehydroxylase which catalyses the formation of deoxycholic acid from cholic acid. In experiments similar to the present ones we showed that deoxycholate concentrations in bile were reduced by speeding up intestinal transit and increased by slowing down transit, with parallel changes in the cholesterol saturation of gall bladder bile and, therefore, in the risk of gallstone formation. ${ }^{24}$ Thus, it is possible that there are far-reaching metabolic effects of changes in intestinal transit time as well as changes in the risk of bowel cancer.

The failure of any intervention to alter $\mathrm{pH}$ in the proximal colon is not surprising as $\mathrm{pH}$ here is likely to depend mostly on the arrival of unabsorbed carbohydrates and their rapid fermentation by caecal anaerobes. ${ }^{48}$

A relatively novel feature of this study is that we used subjects' observations of their stool form as an assessment of colonic function. Previous cross-sectional studies have established that the Bristol stool form scale is sensitive to transit time. ${ }^{26} 2749$ This is the first interventional study to show that change in transit time is accompanied by change in stool form, which further validates the scale as a simple proxy for transit time.

The decrease in SCFA concentration seen in stools when loperamide was taken suggests that any diet or lifestyle changes that lead to constipation can reduce the concentration of SCFA in the distal colon. This may help to explain the prevalence of distal colonic cancers in Western countries. The data from volunteers taking wheat bran and senna suggests that anything which increases intestinal transit rate will beneficially increase the concentration of butyrate in the distal colon independently of dietary intake of fermentable substrate.

We should like to thank the Kellogg Company of Great Britain and the trustees of the United Bristol Health Care Trust for and the trustees of the United Bristol Health Care Trust for their generous support of this work. We would also like to express our appreciation to Dr David Evans, GI Research Unit,
The London Hospital, UK, for help in using the pH telemetry The London Hospital, UK, for help in using the pH telemetry system. The technical assistance of Dr Christine Edwards and
the staff of the Department of Human Nutrition, Glasgow University, York Hill Hospital, Glasgow, is gratefully acknowledged.

1 Macdonald IA, Webb GR, Mahony DE. Fecal hydroxysteroid dehydrogenase activities in vegetarian seventh day adventists, control subjects, and bowel cancer patients. $A m$ f Clin Nutr 1978; 31: S233-8.

2 Hove $\mathrm{H}$, Clausen MR, Mortensen PB. Lactate and $\mathrm{pH}$ in faeces from patients with colonic adenomas or carcinoma. Gut 1993; 34: 625-9.

3 Thornton JR. High colonic pH promotes colorectal cancer. Lancet 1981;i: $1081-2$.

4 Walker ARP, Walker BF, Segal I. Faecal $\mathrm{pH}$ value and its modification by dietary means in South African black and white schoolchildren. S Afr Med f 1979; 55: 495-8.

5 Walker ARP, Walker BF, Segal I. Fecal pH: a constitutional characteristic? S Afr Med F 1988; 73: 672 .

6 Newmark HL, Lupton JR. Determinants and consequences of colonic luminal $\mathrm{pH}$ : implications for colon cancer. Nut Cancer 1990; 14: 161-73.

7 Evans DF, Pye G, Bramley R, Clark AG, Dyson TJ, Hardcastle JD. Measurement of gastrointestinal pH
profiles in normal ambulant human subjects. Gut 1988; 29: 1035-41.

8 Evans DF, Pye G, Opare-Sem P, Kotoh S, nii-Amon-Kotei D. Is colorectal cancer risk increasing in urban Ghanaians. D. Is colorectal cancer risk increasing in
Ghana Medical fournal 1988; 22: 8-16.

9 Walker ARP. Diet, bowel motility, faeces composition and colonic cancer. S Afr Med f 1971; 39: 377-9.
10 Burkitt DP, Walker ARP, Painter NS. Effect of dietary fibre on stools and transit times and its role in the causation of disease. Lancet 1972; ii: 1408-12.

11 Bingham S. Mechanisms and experimental evidence relating dietry fibre (NSP) and starch to protection against large bowel cancer. Proc Nutr Soc 1990; 49: 153-71.

12 Hague A, Manning AM, Hanlon KA, Huschtscha LI, Hart D, Paraskeva C. Sodium butyrate induces apoptosis in human colonic tumor cell lines in a p53-independent pathway: implications for the possible role of dietary fibre in the prevention of large-bowel cancer. Int $\mathcal{F}$ Cancer 1993; 55: $498-505$.

13 van Munster IP, Tangerman A, Nagengast FM. Effect of resistant starch on colonic fermentation, bile acid metabolism, and mucosal proliferation. Dig Dis Sci 1994; 39: 83442 .

14 McIntyre A, Gibson PR, Young GP. Butyrate production from dietary fibre and protection against large bowel cancer in a rat model. Gut 1993; 34: 386-91.

15 Jacobson EA, Newmark HL, Bright-See E, McKeownEyssen G, Bruce WR. Biochemical changes as a result of increased fibre consumption. Nutr Rep Int 1984; 30: 1049-

16 Ehle FR, Robertson JB, van Soest PJ. Influence of dietary fibres on fermentation in the human large intestine. 7 Nutr 1982; 112: 158-66.

17 Fantus B, Frankl W. The mode of action of bran. I. The effect of bran upon composition of stools. $7 \mathrm{Lab}$ Clin Med 1941; 26: $1774-7$.

18 Kim DH, Kang HJ, Kim SW, Kobashi K. pH-inducible $\beta$-glucosidase and $\beta$-glucuronidase of intestinal bacteria. Chem Pharm Bull 1992; 40: 1667-9.

19 Mallet AK, Bearne CA, Rowland IR. The influence of incubation $\mathrm{pH}$ on the activity of rat and human gut flora enzymes. F Appl Bacteriol 1989; 66: 433-7.

20 Stellwag EJ, Hylemon PB. $7 \alpha$-dehydroxylation of cholic acid and chenodeoxycholic acid by Clostridium leptum. $\mathcal{F}$ Lipid Res 1979; 20: 325-33.

21 Paul AA, Southgate DAT. McCance and Widdowson's, The composition of foods. Amsterdam, New York and Oxford: Elsevier/North-Holland Biomedical Press, 1978.

22 Englyst HN, Bingham SA, Runswick SA, Collinson E, Cummings JH. Dietary fibre (non-starch polysaccharides) in cereal products. Fournal of Human Nutrition and Diet 1989; 2: 253-71.

23 Englyst HN, Bingham SA, Runswick SA, Collinson E, Cummings JH. Dietary fibre (non-starch polysaccharides) in fruit, vegetables and nuts. Fournal of Human Nutrition and Diet 1988; 1: 247-86.

24 Marcus SN, Heaton KW. Effects of a new, concentrated, wheat fibre preparation on intestinal transit, deoxycholic acid metabolism and the composition of bile. Gut 1986; 27: 893-900.

25 Mallet AK, Rowland IR, Bearne CA. Modification of rat caecal microbial biotransformation activities by dietary saccharin. Toxicology 1985; 36: 253-62.

26 Probert CSJ, Emmett PM, Heaton KW. Intestinal transit time in the population calculated from self made observations of defecation. $\mathcal{f}$ Epidemiol Community Health 1993; 47: 331-3.

27 O'Donnell LJD, Virjee J, Heaton KW. Detection of pseudodiarrhoea by simple clinical assessment of intestinal transit rate. $B M \mathcal{F} 1990 ; \mathbf{3 0 0 :} 439-40$.

28 Spiller GA, Chernoff MC, Hill RA, Gates JE, Nassar JJ, Shipley EA. Effect of purified cellulose, pectin, and a lowresidue diet on fecal volatile fatty acids, transit time, and fecal weight in humans. Am f Clin Nutr 1980; 33: 754-9.

29 El Oufir E, Flourié B, Varannes SB, Barry JL, Cloarec D, Bornet $\mathrm{F}$, et al. Relations between transit time, fermentation products, and hydrogen consuming flora in healthy Cut 1996; 38: 870-7.

30 Cummings JH, Bingham SA, Heaton KW, Eastwood MA. Faecal weight, colon cancer risk, and dietary intake of nonstarch polysaccharides (dietary fibre). Gastroenterology 1992; 103: 1783-9.

31 Heaton KW, Radvan J, Cripps H, Mountford RA, Braddon FEM, Hughes AO. Defecation frequency and timing, and stool form in the general population: a prospective study. Gut 1992; 33: 818-24

32 Wyman JB, Heaton KW, Manning AP, Wicks ACB. Variability of colonic function in healthy subjects. Gut 1978; 19: 146-50.

33 Cummings JH. Diet and transit through the gut. In: Heaton $\mathrm{KW}$, ed. Dietary fibre: current developments of importance to health. London: Libbey, 1978: 83-95.

34 Tucker DM, Sandsted HH, Logan GM Jr, Klevay LM, Mahalko J, Johnson LK, et al. Dietary fiber and personality factors as determinants of stool output. Gastroenterology 1981; 81: 879-83

35 Lampe JW, Fredstrom SB, Slavin JL, Potter JD. Sex difference in colonic function: a randomised controlled trial. Gut 1993; 34: 531-6.

36 Probert CSJ, Emmett PM, Heaton KW. Some determinants of whole gut transit-time: a population-based study. $Q 7$ Med 1995; 88: 311-5.

37 Cummings $\mathrm{JH}$. The effect of dietary fibre on fecal weight and composition. In: Spiller GA, ed. CRC Handbook of dietary fiber in human nutrition. Boca Raton: CRC Press, 1993: 263-349.

38 Fantus B, Hirschberg N, Frankl W. The mode of action of bran. II. Influence of size and shape of bran particles and of crude fiber isolated from bran. Reviews in Gastroenterology 1941; 8: $277-80$. 
39 Eastwood MA, Kirkpatric JR, Mitchell WD, Bone A, Hamilton T. Effects of dietary supplements of wheat bran and cellulose on faeces and bowel function. BMF 1973; 4: 392-4.

40 Stephen AM, Wiggins HS, Englyst HN, Cole TJ, Wayman $\mathrm{BJ}$, Cummings $\mathrm{JH}$. The effect of age, sex and level of intake of dietary fibre from wheat on large-bowel function in thirty healthy subjects. Br f Nutr 1986; 56: 349-61.

41 Lewis SJ, Heaton KW. The influence of intestinal transit time on faecal pH [abstract]. Gut 1995; 37 (suppl 2): A51.

42 Bardon T, Fioramonti J. Nature of the effects of bran on digestive transit time in pigs. Br F Nutr 1983; 50: 685-90.

43 Hillman L, Peters S, Fisher A, Pomare EW. Differing effects of cellulose, pectin and lignin on stool $\mathrm{pH}$, transit time and weight. Br F Nutr 1983; 50: 189-95.

44 Rowland IR. The influence of the gut microflora on food toxicity. Proc Nutr Soc 1981; 40: 67-74.
45 Goldin BR, Adlercreutz H, Gorbach SL, et al. Estrogen excretion patterns and plasma levels in vegetarian and omnivorous women. Ni Engl f Med 1982, 307: 1542-7.

46 Goldin BR, Gorbach SL. The relationship between diet and rat fecal bacterial enzymes implicated in colon cancer. $\mathcal{F}$ Natl Cancer Inst 1976; 57: 371-5.

47 Reddy BS, Engle A, Katsifis S, Bartram HP, Perrino P, Mahan C. Biochemical epidemiology of colon cancer: effect of types of dietary fiber on fecal mutagens, acid, and neutral sterols in healthy subjects. Cancer Res 1989; 49: 4629-35.

48 Brown RL, Gibson JA, Sladen GE, Hicks B, Dawson AM. Effects of lactulose and other laxatives on ileal and colonic $\mathrm{pH}$ as measured by radiotelemetry device. Gut 1974; 15: 999-1004.

49 Heaton KW, O'Donnell LJD. An office guide to whole-gut transit-time: patients' recollection of their stool form. F Clin Gastroenterol 1994; 19: 28-30. 